\title{
PERICLES Y LA DEFINICIÓN DE DEMOCRACIA (THUC. 2.37.1): ESTADO DE LA CUESTIÓN E INTERPRETACIONES ANTIGUAS DE UN PASAJE CLAVE DEL EPITAFIO
}

\author{
Juan Carlos Iglesias-Zoido \\ Universidad de Extremadura \\ iglesias@unex.es
}

\section{RESUMEN}

El objetivo del presente trabajo es estudiar las diferentes interpretaciones que ha recibido Thuc. 2.37.1. En primer lugar, se ofrece un estado de la cuestión de las diferentes posturas adoptadas por la crítica moderna a la hora de traducir este pasaje. En segundo lugar, se lleva a cabo un análisis de cómo este texto fue interpretado en la Antigüedad.

Palabras Clave: Tucídides, Pericles, epitafio, Thuc. 2.37.1, democracia, traducciones.

PERICLES AND THE DEFINITION OF DEMOCRACY (THUC. 2.37.1): STATE OF THE QUESTION AND ANCIENT INTERPRETATIONS OF A KEY PASSAGE OF THE FUNERAL ORATION

\section{ABSTRACT}

The objective of this paper is to study the different interpretations that Thuc. 2.37.1 has received. First, it offers a state of the question of the different positions adopted by modern criticism on translating this passage. Secondly, an analysis of how this text was interpreted in Antiquity is carried out.

KeYwords: Thucydides, Pericles, funeral oration, Thuc. 2.37.1, democracy, translations.

El presente trabajo ${ }^{1}$ tiene como objetivo estudiar las diferentes interpretaciones que ha recibido un pasaje clave del epitafio tucidideo (Thuc. 2.37.1) ${ }^{2}$. Unas palabras que, puestas en boca de Pericles, suelen ser consideradas como uno de los pilares sobre los que se basa el concepto de democracia en sus orígenes y que, además, tienen múltiples implicaciones para la comprensión de la obra de Tucídides ${ }^{3}$.

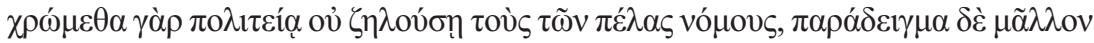

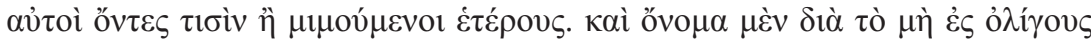

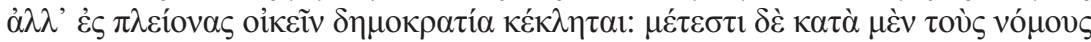

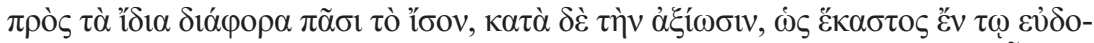

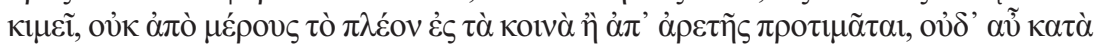

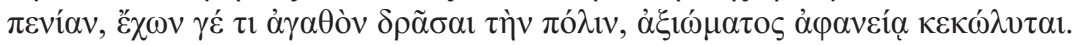


Autores de todo tipo a lo largo de la historia han prestado gran atención a estas palabras de Pericles y las han convertido en un paradigma ideológico y en una auténtica "piedra de toque" para interpretar no solo el epitafio sino incluso la figura del estadista ateniense $e^{4}$. Sin embargo, hoy en día, comprender el auténtico significado tanto del concepto de democracia enunciado por Pericles en 2.37.1 como la verdadera finalidad del epitafio es una tarea compleja en la que no se pone de acuerdo la crítica. Para comprender las causas de las diferentes traducciones que ha recibido este pasaje, en el presente trabajo ofrecemos, en primer lugar, un estado de la cuestión de la interpretación de Thuc. 2.37.1 por parte de la crítica y, en segundo lugar, como inicial aportación de un conjunto de estudios sobre la historia de cómo ha sido entendido este pasaje hasta el día de hoy, llevaremos a cabo un análisis de cómo este texto fue comprendido en la Antigüedad.

\section{THUC. 2.37.1: ESTADO DE LA CUESTIÓN}

1.1. Dentro del ámbito de la filología griega, hay dos grandes corrientes interpretativas sobre el verdadero significado de este pasaje clave de Tucídides dentro del contexto del discurso fúnebre al que pertenece:

La primera defiende que el epitafio en su conjunto ha de ser interpretado como un auténtico manifiesto de elogio de la democracia por parte de Pericles y que, por lo tanto, la definición de este régimen político que se ofrece en 2.37 .1 ha de leerse

\footnotetext{
${ }^{1}$ Este trabajo se enmarca en el Proyecto de Investigación de Excelencia FFI2015-64765-P y en el Grupo de Investigación "Arenga" (HUM-023) de la UEX.

${ }^{2}$ Entre la inmensa bibliografía dedicada a estudiar el epitafio y su papel dentro del género epidíctico, se destacan de manera especial dos trabajos publicados en 1981: Loraux (1981), ahora con traducción española en Loraux (2012), y Ziolkowski (1981). Cf. también, como trabajos reseñables desde diversas perspectivas, los de Pohlenz (1948), Flashar (1969), Strasburger (2009), publicado originalmente en 1958, Kakridis (1961), Turasiewich (1995), Sicking (1995) y Grethlein (2005 y 2010). Sobre el contexto del discurso fúnebre, sigue siendo fundamental el estudio de Loraux (2012: 37-63) publicado originalmente en 1981, quien señala que "asignar al discurso su lugar en esa 'realidad' (el nómos de los funerales) equivale a determinar lo que el discurso le debe a ella y, por ende, lo que le aporta" (pp. 38-39). Sobre aspectos complementarios de ese ámbito físico, cf. Bosworth (2000) y los comentarios de Hornblower (1991) sobre este pasaje.

${ }^{3}$ Sobre la consideración de la figura de Pericles en la Antigüedad, remitimos a los estudios de Banfi (2003) y Mossé (2007) además de, con bibliografía actualizada, Azoulay (2010), Martin (2016) y Sammons II (2016). En la obra de Tucídides, tenemos tres discursos en estilo directo (Thuc. 1.140-4, 2.35-46 y 2.60-64) y uno en estilo indirecto (Thuc. 2.13) pronunciados por este personaje. Sobre el conjunto de los discursos de Pericles, cf. la aportación fundamental de Romilly (1947). Cf. también Foster (2010) con bibliografía actualizada en pp. 1-7. Entre los trabajos recientes dedicados a interpretar la figura de Pericles en la obra de Tucídides, cf. Will (2003), Foster (2010) y Christodoulou (2013).

${ }^{4}$ Sobre la recepción e influencia de la figura de Pericles a lo largo de la historia, cf. Mossé (2007: 225-246), Azoulay (2010: 164-235), Dabdab Trabulsi (2011) y Will (2016).
} 
dentro de las claves de una teoría de la democracia radical ya desarrollada a lo largo del siglo V a. C. 5 . En otras palabras, este texto de Pericles, parte de una reflexión más amplia del político ateniense sobre el modo de conjugar los intereses públicos con los privados, coincidiría en sus puntos esenciales con esa teoría democrática y no ocultaría ningún tipo de crítica a sus excesos y desviaciones. En defensa de esta interpretación se han destacado tanto los múltiples puntos de contacto de las palabras del epitafio con otros textos claves de la literatura griega contemporánea, como las Suplicantes de Esquilo y de Eurípides ${ }^{6}$ como las diferencias con la Constitución de los Atenienses del Pseudo-Jenofonte ${ }^{7}$, que son respectivamente ejemplos destacados de posturas democráticas u oligárquicas. Una interpretación defendida en los últimos años por autores como Raaflaub, Brock, Musti o Hansen. Así, para los defensores de la primera corriente, estas palabras de Pericles se encuadran dentro de una línea de pensamiento bien asentada en la Atenas de ese momento; son claramente concordantes con su contexto contemporáneo y, por lo tanto, no ofrecen una visión personal del político sobre lo que era la democracia de aquellos años. Hay que entender que Pericles, por medio de estas palabras, hace un sincero elogio de la democracia. Es más, quienes lo interpretan así, consideran que desde el comienzo del pasaje (la indicación $\chi \rho \omega ́ \mu \varepsilon \theta \alpha$

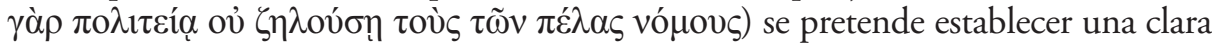
diferencia con respecto a otros regímenes políticos y que esta es la causa última de la definición de democracia que se ofrece en el texto\%. Un enfoque que encuentra

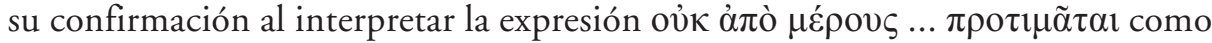
una referencia positiva al sistema de elección a la hora de ocupar puestos públicos que caracteriza a la democracia ateniense frente a las implantadas en otros lugares, en las que se primaba la pertenencia a una clase social o a un partido ( $\dot{\alpha} \pi$ ò $\mu \varepsilon \dot{\varepsilon} \rho o v \varsigma)$ antes que la valía personal $\left(\dot{\alpha} \pi^{\prime} \dot{\alpha} \rho \varepsilon \tau \tilde{\eta} \varsigma\right)^{10}$.

${ }^{5}$ En este sentido, cf. el enfoque de trabajos recientes como el de Will (2016: 10), quien defiende que el epitafio "reveals Thucydides's ideal visión of democracy for Athens".

${ }^{6}$ Cf. sobre todo el análisis de estos pasajes por Musti (1995). Cf. especialmente el discurso patriótico de Teseo en Eur. Supp. 404-408. Del mismo modo, cf. el reflejo de las ideas de Pericles en Menex. 238c7-d2 e Isoc. Panath. 153.

${ }^{7}$ Cf. Caballero López (1982) para un estado de la cuestión (fechas, autoría y lengua) hasta la década de los 80 y la idea de que es una obra compuesta hacia el 424 a.C. Osborne (2004) la sitúa hacia 413 a.C. y Hornblower (2000) defiende una fecha tardía (s. IV a.C.) y sostiene que los puntos de contacto se deben a la posible influencia de la obra de Tucídides sobre su autor.

${ }^{8}$ Cf. Raaflaub (1990) y (1997), Brock (1991), Musti (1995) y Hansen (2008).

${ }^{9}$ Cf. Gomme (1948), Grant (1971) y Harris (1992). En cierto modo, este enfoque establecería una relación con el texto de Heródoto 3.80 donde compara el historiador la democracia con la monarquía y la oligarquía.

${ }^{10}$ Las diferentes interpretaciones señaladas por Hornblower (1991: 300), entre las que se destacan dos: "in rotation" y "on the basis of party". Gomme (1948), Rusten (1989) y Hornblower (1991) optan por el sentido "in rotation" frente a autores como Landmann (1974). Para justificar el sentido de partido político suele utilizarse otro pasaje de Tucídides (6.39), donde el siracusano Atenágoras señala que los oligarcas constituyen un $\mu$ śpos de la politeía. 
La segunda corriente interpretativa pone en duda la existencia, en el siglo $\mathrm{V}$ a.C., de una teoría democrática perfectamente establecida y asentada. Es decir, aunque hay textos que versan sobre la democracia o sobre sus puntos de contacto y diferencias con otros tipos de regímenes políticos, en el siglo $\mathrm{V}$ a.C. no puede sostenerse la existencia de una auténtica "teoría política" sobre la democracia ${ }^{11}$. Para alcanzar este grado de reflexión habría que esperar hasta los teóricos del siglo siguiente como Aristóteles. Por lo tanto, en un pasaje como 2.37.1 podría interpretarse que Tucídides no pone en boca de Pericles ideas que pertenezcan a una teoría perfectamente asentada, sino que son fruto de una visión personal sobre este régimen político. Estas palabras reflejarían la ideología del líder ateniense (o, en todo caso, la del historiador Tucídides), dejando entrever, gracias al empleo de conceptos propios de un lenguaje de tipo oligárquico, una cierta visión "aristocrática" de la democracia. Una interpretación que, defendida originalmente por autores como Jones, Momigliano o Finley, ha sido recuperada por Loraux y, sobre todo, por Canfora, defensor de la tesis

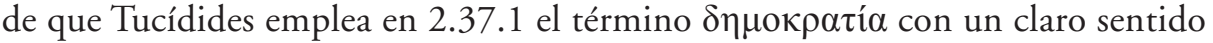
despectivo planteado como auténtica antítesis frente al concepto clave de "libertad" que estructura buena parte del discurso ${ }^{12}$.

Dependiendo de cada una de las dos interpretaciones generales del epitafio, la frase en la que Pericles ofrece la definición de democracia (y en concreto la expre-

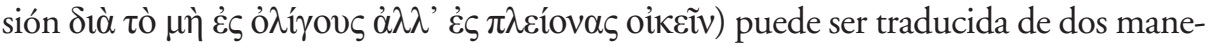
ras muy distintas: como que el gobierno de Atenas se pone en manos de la mayoría o como que la administracion de la ciudad se ejerce en favor de esa mayoría. Todo depende del valor que Tucídides le otorgue a los sintagmas $\dot{\varepsilon} \varsigma$ ỏ $\lambda \dot{y}$ ov $\varsigma$ y $\dot{\varepsilon} \varsigma \pi \lambda \varepsilon i ́ o v \alpha \varsigma$

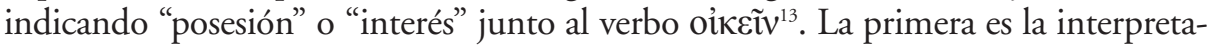
ción defendida por autores como Poppo, Classen y Steup, Gomme, Kakridis, Pavón, de Romilly, Vrestska, Rhodes, Raaflaub, Harris o Musti ${ }^{14}$. La segunda es la sostenida, con diferentes matices, por Sheppard y Evans, Oliver, Ostwald, Rusten, Hornblower o Canfora ${ }^{15}$. Como consecuencia de estas dos interpretaciones, en un extremo se sitúan aquellas traducciones, como la de Rex Warner, de gran influencia en el mundo

${ }^{11}$ Cf. al respecto Forsdyke (2001), con especial atención a Heródoto.

${ }^{12}$ Cf. Jones (1957), Momigliano (1960), Finley (1960 y 1980), Loraux (1981), Canfora (2004: 11-12).

${ }^{13}$ Classen ya adujo una serie de pasajes en favor de la primera opción: Thuc. 8.38.1, 8.53.3 y 8.89.2. El problema es que se trata de ocasiones en las que no aparece el verbo oikeivv. Por otra parte, la misma ambigüedad presente en 2.37.1 es perceptible en otros pasajes como Thuc. 5.81.2 y 8.97.2.

${ }^{14}$ Cf. Poppo (1834: vol. III, parte 2, pp. 161-166), Classen - Steup (1914: vol. II, pp. 91-92, Pavón (1946), Gomme (1948), de Romilly (1962: vol. II, pp. 95-96), Vretska (1966), Rhodes (1988), Raaflaub (1990), Harris (1992), Musti (1995).

${ }^{15}$ Cf. Sheppard - Evans (1870: 190), Oliver (1945), Kakridis (1961), Ostwald (1987), Rusten (1989) y Canfora (2004). 
anglosajón, que priman el significado etimológico del término $\delta \eta \mu о \kappa \rho \tau i ́ \alpha$ y que, en consecuencia, ponen el énfasis en el hecho de que el poder político reside en el pueblo: "Our constitution is called a democracy because power is in the hands not of a minority but of the whole people"16. En el otro extremo, como señala Hornblower, estarían aquellas versiones que ponen de manifiesto lo que consideran que es una sutil diferencia que no puede pasarse por alto: "It is true that we are called a democra$\mathrm{cy}$, for the administration is run with a view to the interests of the many, not of the few"17. Desde este punto de vista, Pericles no afirmaría que el poder estuviera en manos del pueblo, sino que se administraban los asuntos públicos en beneficio de la mayoría y no de unos pocos. El pueblo no aparece por lo tanto como sujeto activo sino como ente pasivo. En palabras de Nicole Loraux: "el demos aparece como un beneficiario del régimen más que como pueblo soberano"18. De este modo, aunque el orador afirma que las clases bajas desempeñan un papel (Pericles dice expresamente que la

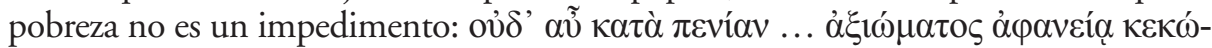

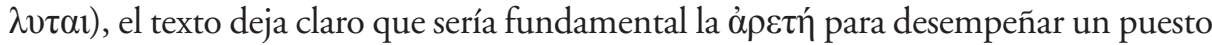

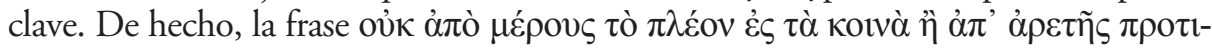
$\mu \tilde{\alpha} \tau \alpha \iota$ debería ser entendida mejor como una contraposición con respecto al sistema social cerrado de Esparta, al dejar claro que en Esparta la pertenencia a una clase social

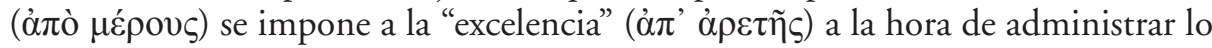
común y que se prefiere, por lo tanto, un sistema rotativo frente a otro basado en el mérito ${ }^{19}$.

1.2. Junto a las dificultades de interpretar varios de los sintagmas de 2.37.1, la crítica también ha destacado que estas palabras de Pericles, a pesar de su fama como texto clave de la democracia ateniense, se quedan extrañamente cortas. De hecho, no sirven para conocer la esencia del régimen democrático de aquellos años del último tercio del siglo $\mathrm{V}$ a.C., ya que ofrecen un cuadro llamativamente incompleto ${ }^{20}$. En efecto, si tuviéramos que elegir dos términos para definir la democracia griega en sus orígenes, habría un claro consenso en que estos serían los de isonomía

${ }^{16}$ Cf. la traducción de 2.37.1 de Rex Warner (1954: 117). Hansen (2008: 17) destaca que esta traducción puede estar influida por el comentario de Gomme (1956: 107-108), quien señala "that demokratia can mean either simply majority rule in a state where all citizens have the vote ... or the consistent domination of the state by the masses".

${ }^{17}$ Cf. Hornblower (1991: 298). En esta línea, cf. Regenbogen (1949: 115): "Ihr Name heisst, weil wir nicht in Rücksicht auf wenige, sondern in Rücksicht auf die grössere Zahl der Bürger leben, Volksherrschaft", traducción que se aparta radicalmente de las versiones alemanas previas, tal y como señala Kakridis (1961: 25).

${ }^{18}$ Cf. Loraux (2012: 187).

${ }^{19}$ Cf. Gomme (1948), Rusten (1989) y Hornblower (1991), que optan por el sentido “in rotation" en vez de "according to rank or family".

${ }^{20}$ Frente a la tesis defendida por Hansen (2008). 
e isegoría. Igualdad ante la ley e igualdad a la hora de intervenir ante la asamblea ${ }^{21}$. A esos dos derechos de los ciudadanos atenienses, ganados a lo largo del siglo $\mathrm{V}$ a.C., habría que añadir un elemento fundamental que debemos precisamente a Pericles: la misthophoría ${ }^{22}$. Segun nos informa Aristoteles (Ath. Pol., 27.3-4), Pericles al encontrarse en desventaja frente al liderazgo de Cimón habría instituido un mecanismo para ganarse el apoyo de las masas, que consistió inicialmente en el cobro por parte de los ciudadanos de un estipendio (misthós) por desempeñar la funcion judicial (luego ampliado al resto de las magistraturas). Innovación que podría haber sido una forma de patronazgo público y de resguardo para los pobres frente al patrocinio privado o individual de los ricos, pero que acabó generando muchas críticas por parte de sus contemporáneos por los excesos que generó. Pues bien, ¿`cuál es la presencia de estos elementos característicos del régimen democrático en el discurso de Pericles?

En primer lugar, en el pasaje estudiado está presente la isonomía (que es claramente destacada como un valor esencial dentro de la esfera privada: $\mu \varepsilon ́ \tau \varepsilon \sigma \tau t ~ \delta \dot{~} \kappa \alpha \tau \grave{~}$

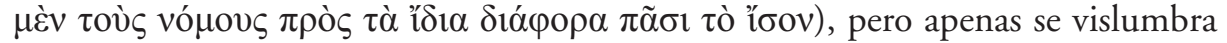
la isegoría $a^{23}$. Es como si la igualdad de todos los ciudadanos ante la ley no tuviera su directo correlato con respecto a su participación activa en el ámbito político. Como si la idea subyacente fuera que ese ámbito político estaba reservado a una élite, como así ocurría en la práctica. Pero, sobre todo, lo que es especialmente llamativo, es que en ningún momento Pericles alaba o cita la misthophoría, que él mismo introdujo para conseguir que todos los ciudadanos pudiesen participar en los puestos públicos. Algo muy criticado por Platón en el Gorgias (cf. 515 y 519), donde señalaba que este pago hizo peores a los atenienses y, sobre todo, convirtió a Pericles en un mal gobernante. Esta ausencia de la misthophoría en el presente texto es muy llamativa. De algún modo es como si el propio Pericles (o el historiador Tucídides) omitiese un procedimiento que, aunque facilitó la participación de las clases populares, también acabó por desvirtuar al régimen democrático. De hecho, el propio historiador en uno de los escasos pasajes donde ofrece su propia opinión sobre el desarrollo de uno de los hechos más importantes del final de la guerra, la caída del régimen de los 400, destaca y ve con buenos ojos que una de las decisiones que adoptó la asamblea ateniense cuando traspasó el poder a los Cinco Mil fue precisamente "que nadie percibiera sueldo del estado por ningún cargo público y que, si alguno lo hacía, que lo declararan maldi-

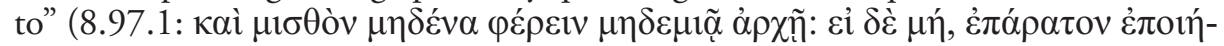
$\sigma \alpha v \tau o)$. A la vista de una opinión tan negativa del propio Tucídides, el silencio de Pericles sobre la misthophoría en 2.37.1, sería un dato muy significativo y podría poner de manifiesto que en el momento en el que este discurso fue realmente elaborado (a finales del siglo $\mathrm{V}$ a.C.) ya no era un dato visto de manera favorable.

${ }^{21}$ Cf. al respecto Cartledge (2016: 114).

${ }^{22}$ Cf. Pébarthe (2007).

${ }^{23}$ Cf. Vlastos (1964: 15-16) para una visión negativa de la presencia de la isegoría en 2.37.1 frente a lo defendido por Vretska (1966: 111), Flashar (1969: 18) o Raaflaub (1997). 
En segundo lugar, Pericles destaca en 2.37.1 un elemento básico para determinar la conveniencia o no de la participación en la vida de la ciudad: la "excelencia" o areté. De hecho, una de las grandes aportaciones de Loraux fue comprobar que Pericles, como ocurre con otros oradores que pronunciaron epitafios, elabora el elogio del régimen democrático utilizando un vocabulario claramente aristocrático ${ }^{24}$. La afirmación general de que la democracia no llegó a conseguir un lenguaje propio y que no pudo evitar la insistencia en el valor de la areté tiene en el caso de Pericles uno de sus mejores ejemplos concretos. De hecho, en Thuc. 2.37.1, Pericles coloca el concepto de areté por encima de la división social entre ricos y pobres: no se dificulta que el pobre aporte su grano de arena a los asuntos públicos si su valía así se lo permite. Una participación que, por lo tanto, es vista como algo claramente residual ya que depende de un concepto aristocrático que está muy alejado del objetivo igualitario que, nominalmente, tuvo la democracia radical ateniense.

En tercer lugar, la crítica también ha señalado que lo que Pericles hace realmente en este elogio es destacar el modo de vida ateniense más que su sistema político: la libertad que rige su conducta ${ }^{25}$. Al comenzar esta sección del discurso, el propio orador dice que su elogio se basará en tres elementos: régimen político, maneras de ser y actitudes. Lo llamativo es que el elemento central de 2.37.1, la constitución política o politeía, apenas recibe atención a lo largo del discurso y el elogio o épainos se centra de manera abrumadora sobre esas maneras de ser y sobre esas actitudes que conforman la esencia del espíritu ateniense $e^{26}$. Un espíritu que está caracterizado por la libertad pero no por un régimen democrático, que en cierto modo da la impresión de que era visto por Pericles como un "mal menor" ${ }^{27}$. Así, tras dejar de lado expresamente aspectos que podrían ser considerados como "típicos" (las empresas guerreras de los antepasados) al no pretender hacer un discurso extenso sobre temas bien conocidos por los oyentes, Pericles afirma que va a hacer una "demostración" ( $\delta \eta \lambda \omega ́ \sigma \alpha \varsigma)$ sobre tres cuestiones: la "actitud" (epitédeusis) con la que los atenienses han conseguido su supremacía, la forma de ser (trópoi) que ha fundamentado esa supremacía y el régimen político (politeía) que les ha hecho ser un modelo. El Pericles que nos muestra Tucídides se aparta de lo usual en un epitafio desde las primeras palabras del proemio (Thuc. 2.35.1), al establecer una primera oposición entre lo que suele decir la mayor parte de los que han ocupado ese lugar a la hora de alabar a Atenas

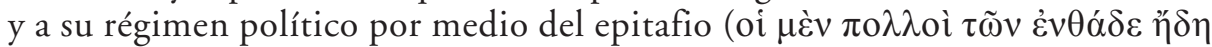

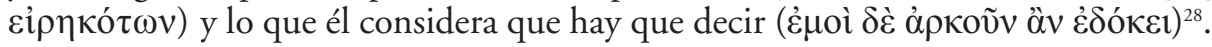
Una contraposición en la que Pericles insiste más adelante, al señalar expresamente

${ }^{24}$ Cf. Loraux (2012: 186-207).

${ }^{25}$ Cf. especialmente la interpretación de Landmann (1974).

${ }^{26}$ Cf., en este sentido, Cartledge (2016) 97, quien señala que se trata sobre todo de una especie de himno en honor "of the Athenian democratic way of life more generally".

${ }^{27}$ Cf. la tesis principal de Canfora (2004).

${ }^{28}$ Cf. Grethlein (2005) sobre la relación entre el epitafio y el capítulo metodológico. 


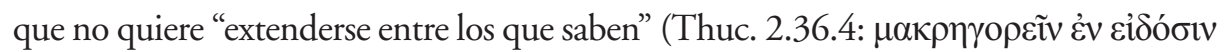

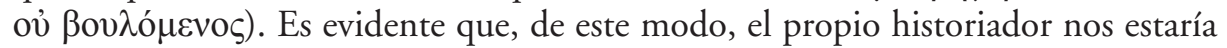
dando la clave de que va a hacer hablar a Pericles de un modo muy personal y que su discurso fúnebre va más allá del simple cumplimiento de los requisitos de la ceremonia tradicional que tan detalladamente ha descrito en el engarce previo (Thuc. $2.34)^{29}$. Lo llamativo, por lo tanto, es que Tucídides apenas dedica espacio a lo que debía ser su parte esencial, el régimen político (politeía), y que, por el contrario, Pericles se dedica a ensalzar algo que es previo y, en cierto modo, independiente del sistema político contemporáneo: la actitud y la forma de ser que caracteriza a los atenienses. El elogio de Atenas, por lo tanto, es planteado por Pericles dentro de la obra de Tucídides como un canto a la libertad que rige el reconocido "Athenian way of life" antes que como una alabanza de la democracia ${ }^{30}$.

1.3. En este sentido, al tratarse de un discurso retóricamente muy elaborado que se aparta conscientemente del camino marcado por la tradición fúnebre del epitafio ${ }^{31}$, la crítica también ha destacado la necesidad de estudiar el discurso teniendo en cuenta el contexto propiamente historiográfico en el que se inserta. Frente a la opinión mantenida durante mucho tiempo de que discursos como éste eran un reflejo fiel de lo realmente pronunciado (estos discursos representan las palabras realmente pronunciadas por los oradores $)^{32}$, la crítica en los últimos años defiende que este discurso es un producto de la metodología del historiador que se plasmaría en dos cuestiones clave.

Por una parte, hay autores que defienden que el epitafio fue utilizado por el historiador ático para caracterizar a Pericles y para presentar rasgos de su pensamiento que habrían sido considerados claves para sus lectores ${ }^{33}$. Motivos ambos que podrían justificar, dentro de un ámbito ceremonial y retórico tan claramente determinado, la presencia de una serie de elementos diferenciadores dentro del discurso, que habrían sido utilizados por Tucídides para caracterizar al orador o para resaltar alguna faceta concreta de su pensamiento. Esta última característica es la que nos ha de permitir comprender las razones por las que Tucídides presentó a Pericles haciendo un elogio del sistema político ateniense de un modo diferente de lo que encontramos

${ }^{29}$ Además, en esta misma introducción, el historiador incide en una idea ampliamente expresada en su obra: la primacía de la acción (érgon) sobre el discurso (lógos). Sobre el papel desempeñado por los engarces en la obra de Tucídides, cf. Iglesias-Zoido (2006).

${ }^{30}$ Cf., en este sentido, Nichols (2015: 24-50) y Cartledge (2016: 97): “... the oration is less of a hymn to democracy in a constitutional sense ... than to the Athenian democratic way of life more generally: what Aristotle would call 'upbringing and customs/habits' (Politics 1292b15-18)".

${ }^{31}$ Sobre la base retórica del epitafio, cf. Ziolkowsky (1981) y Loraux (1981).

${ }^{32}$ Cf., sobre todo, Gomme (1956), Kagan (1991), Musti (1995).

${ }^{33}$ Cf., por ejemplo, Foster (2010: 1): “(Thucydides) composed Pericles' speeches to display Pericles' character and views to the reader”. Cf. también Christodoulou (2013) sobre la relación entre personaje histórico y representación literaria. 
en otros epitafios contemporáneos más fieles a la idea de resaltar las acciones gloriosas llevadas a cabo por los antepasados.

Por otra parte, hay autores que inciden en una vieja polémica sobre si el epitafio representa fielmente las palabras pronunciadas por Pericles en el 430 a.C. o si, por el contrario, es una composición de Tucídides escrita al final de la guerra con el objetivo de defender a Pericles de los duros ataques que recibió a finales del siglo V a.C. ${ }^{34}$. Todo ello ha llevado a amplios sectores de la crítica a especular sobre el auténtico sentido que el historiador podía haber dado a estas emblemáticas palabras de Pericles en función de su visión sobre el papel realmente jugado por el político en el desarrollo de la guerra, del momento concreto en que este discurso fue elaborado o, incluso, de las ideas políticas defendidas realmente por Tucídides. En este sentido, la crítica ha relacionado esta definición de la democracia con un pasaje clave del libro VIII en el que Tucídides da su opinión sobre la que, desde su punto de vista, fue la mejor politeía que conoció Atenas. Para el historiador, el mejor régimen del que, en su opinión, disfrutaron los atenienses, coincide con la denominada "Constitución de los Cinco Mil" implantada en Atenas en el 411 como reacción a la extremadamente oligárquica "Constitución de los Cuatrocientos" 35 . En opinión del historiador, "durante el primer periodo, al menos en mi tiempo, a mí me parece que los atenienses han disfrutado de su mejor forma de gobierno" (

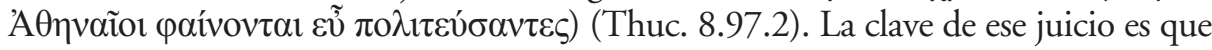
este sistema, en su opinión, era una combinación moderada de los intereses de los pocos

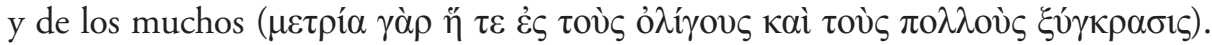
En este sentido, hay autores que consideran que Tucídides defendía ideas oligárquicas frente a quienes consideran que esta sería una manifestación de cómo entendía que debía ser el régimen democrático como una manifestación temprana de lo que luego se denominó en el siglo IV "constitución mixta". Pero, sobre todo, la clave está en cómo puede casar esta afirmación con la visión que Tucídides tenía de la democracia bajo Pericles. En este sentido, habría que destacar claros puntos de contacto entre la definición de Pericles de lo que era el régimen democrático, el elogio póstumo que le dedica el historiador (2.65.10) en el que destaca que en la teoría era una democracia pero en la realidad era el gobierno del primer ciudadano y esta opinión personal sobre la politeía de los Cinco Mil como la mejor constitución que conoció Tucídides al ser el resultado de la combinación moderada de los intereses de los pocos

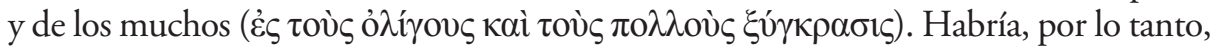
un punto de contacto entre estos pasajes desde el punto de vista de la ideología tucididea: Pericles defendería un concepto de democracia moderada en 2.37.1 que, en palabras de Tucídides era una democracia radical en apariencia pero que realmente

${ }^{34}$ La segunda interpretación (“Apologientheorie”) fue defendida por Schwartz (1919), y fue seguida con distintos matices por Schadewaldt (1929: 39-41), de Romilly (1947) y Flashar (1969).

${ }^{35}$ Cf. al respecto Ste. Croix (1956), Donini (1969), Kirkwood (1972) y Sancho Rocher (1994). 
era el gobierno del primer ciudadano (2.65); un régimen que, ante la ausencia de un líder como Pericles, se habría intentado reproducir al final de la guerra en el caso de la Constitución de los Cinco Mil, cuya característica más destacada era la moderación (8.97.2). De este modo, para Tucídides, la politeía de los Cinco Mil tendría puntos en común con la politeía que conoció Atenas bajo Pericles ${ }^{36}$. Este argumento permitiría defender que 2.37.1 es el resultado de una reelaboración tardía de las palabras originales de Pericles a la vista de todo lo sucedido desde su pronunciación hasta el final de la guerra.

1.4. En definitiva, por sus particularidades y múltiples implicaciones formales, historiográficas y contextuales, es evidente que la determinación del auténtico significado de esta definición de la democracia que se ofrece en 2.37.1 es una de las vexatae quaestiones a las que se tiene que enfrentar la crítica tucididea ${ }^{37}$. Dependiendo del enfoque del intérprete, puede modificarse en una u otra dirección el significado y, por lo tanto, la traducción de un texto que, como es propio de Tucídides, ha sido elaborado con una sintaxis deliberadamente compleja y ambigua. Como señala Ober, "Pericles' funeral oration is deeply complex and often seemingly deliberately ambiguous, both in syntax and in its presentation of the polis"38. Una ambigüedad premeditada que, en ocasiones, ha llegado a ser considerada como contradictoria. Hay quien incluso llega a considerar que Tucídides ofrece en el epitafio una imagen conscientemente contradictoria de Atenas al no poder compaginar en un todo uniforme y coherente (de ahí las numerosas antítesis que jalonan el texto) los diferentes matices del discurso ${ }^{39}$.

A la vista de este complejo estado de la cuestión que hemos ido desgranando, es evidente que alcanzar una conclusión plenamente satisfactoria sobre el significado de 2.37.1 no es tarea fácil recurriendo a argumentos exclusivamente lingüísticos, ya que, como hemos podido comprobar, unas mismas palabras son interpretadas desde diferentes perspectivas. Consideramos que, ante este complejo panorama, es preciso seguir un camino complementario que nos permita profundizar en un ámbito al que la crítica no ha prestado la suficiente atención y que puede permitir aportar luz a esta cuestión: la historia del propio proceso de la interpretación de este pasaje. En efecto, consideramos que llevar a cabo un análisis de cómo estas palabras dentro del conjunto del epitafio han sido interpretadas tanto en la Antigüedad como en épocas posteriores nos ha de permitir como mínimo comprender las causas que están detrás de

${ }^{36}$ Cf. Donini (1969).

${ }^{37}$ Sobre cuestiones generales de la traducción de Tucídides, cf. Greenwood (2015).

${ }^{38}$ Cf. Ober (2011: 84).

${ }^{39}$ Edmunds (1975: 46-47) señala que, en el epitafio de Pericles, "the Athenian citizen incorporates a series of contradictory traits" expresados estilísticamente en una densa estructura de antítesis. Una idea ya apuntada por Kakridis (1961: 31). 
las diferentes traducciones que hoy en día se siguen planteando sobre este pasaje del epitafio. Tal y como Lambert y Robyns han destacado, las diferentes traducciones de un texto concreto (sobre todo si es tan problemático como el que tenemos entre manos) pueden ser entendidas como un producto histórico que se manifiesta en una cadena de interpretaciones. El texto traducido no debe ser visto entonces como el resultado final de una dicotomía estática con respecto al texto original, sino como un "signo" en sí mismo, sujeto a otras posibles interpretaciones que dependen de la interacción de diferentes códigos y modelos normativos ${ }^{40}$. Una consideración metodológica que creemos que es de especial utilidad en el caso de Thuc. 2.37.1. Las traducciones de hoy no dejan de ser la herencia de interpretaciones del texto que se generaron en épocas muy anteriores y que, a lo largo de un largo proceso, han mantenido su vigencia hasta la actualidad. Saber cómo y por qué surgieron y evolucionaron esas interpretaciones puede ayudarnos a comprender cómo es posible que, hoy en día, haya autores contemporáneos que sigan defendiendo traducciones contradictorias de un mismo texto. Como una primera etapa de este camino que continuaremos en varios estudios futuros, en la segunda parte de este trabajo nos centraremos en analizar las interpretaciones antiguas del texto en cuestión.

\section{INTERPRETACIONES ANTIGUAS DE 2.37.1}

2.1. Hemos de comenzar por los escolios de la Historia de Tucídides no solo por tratarse de textos que suelen ser fieles a las interpretaciones comúnmente aceptadas en la Antigüedad, sino también a causa de la enorme influencia que han tenido sobre el modo en que autores de épocas posteriores han leído este texto. Este instrumento exegético proporciona un testimonio esencial sobre la interpretación de este pasaje y nos ofrece una visión, por parcial que realmente sea, de cómo los lectores de la Antigüedad tardía (época más probable de datación de estos comentarios) entendían este texto ${ }^{41}$. Aunque los comentarios conservados no son más que una parte del aparato explicativo que, siglos después de que fuera redactado, los antiguos ya necesitaban para comprender el significado del texto de Tucídides, es destacable que el grueso de los escoliastas incidían en tres ideas esenciales ${ }^{42}$.

${ }^{40}$ Cf. Lambert - Robyns (1997).

${ }^{41}$ Sobre los escolios de Tucídides, cf. el texto en las ediciones de Hude (1927) y Kleinlogel Alpers (2019). Sobre las características de estos escolios, siguen siendo fundamentales los trabajos de Luschnatt (1954) y especialmente Kleinlogel (1964, 1998 y 2011). En cuanto a la época concreta a la que pertenecen los escolios de Tucídides conservados no hay un acuerdo total. Luzzatto (1993) defiende que los escolios conservados en los manuscritos medievales proceden de un arquetipo tardío (con ejemplos como el ms. Plut. 69.2 de la Biblioteca Medicea Laurenziana), mientras que Kleinlogel (1964: 235) y (1998: 34-37) retrasa la fecha hasta el siglo IX d.C.

${ }^{42}$ El texto de 2.37.1 también se conserva en testimonios papirológicos claves como el POxy 583 col. 15, ll. 7-11, fechado en torno al siglo II d. C., que contiene pasajes y escolios de Thuc. 2.1-45. 
La primera idea es la clara y directa contraposición que estos lectores antiguos consideran que Tucídides estableció entre el sistema político de Atenas y el desarrollado por su principal enemigo en la Guerra del Peloponeso: Esparta. De hecho, la primera frase de 2.37 .1 con respecto a la originalidad del régimen

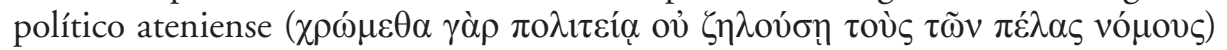
es interpretada por los escoliastas como el comienzo de la à $\gamma \omega \gamma \eta ́$ ( $\tau$ ò $\delta \varepsilon v ́ \tau \varepsilon \rho o v$

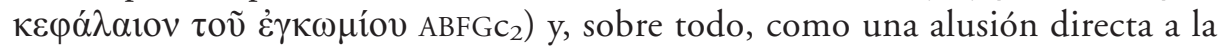
politeía espartana, que, a través de Licurgo, habría imitado las leyes de cretenses y

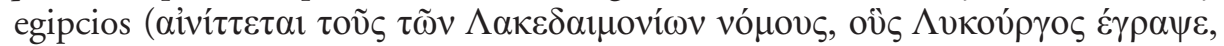

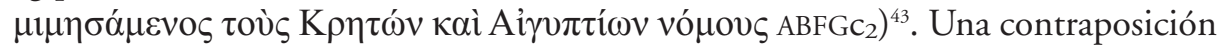
que, aunque no se nombre nunca directamente a Esparta, está latente a lo largo de todo el epitafio. Atenas, frente a sus enemigos lacedemonios, parece presentarse como un ejemplo indiscutible de vida cívica y democrática digna de emulación frente a un régimen militarizado y deshumanizado en el que predomina el duro y tedioso entrenamiento para hacer la guerra. Una comparación que, sobre todo, se hace claramente explícita en Thuc. 2.39, donde Pericles describe las diferencias entre atenienses y espartanos «en las ejercitaciones de las cosas de la guerra» (2.39.1: $\tau \alpha \tilde{\iota} \varsigma \tau \tilde{\omega} \nu \pi \mathrm{o} \lambda \varepsilon \mu 1 \kappa \tilde{\omega} \nu \mu \varepsilon \lambda \varepsilon \dot{\varepsilon} \alpha \alpha \varsigma)$. Tras señalar que los atenienses ofrecen una ciudad que está abierta a todos y que no impide que los extranjeros puedan ver los preparativos de guerra, el historiador hace dos afirmaciones esenciales. La primera tiene que ver con el comportamiento de ambos pueblos cuando luchan en una guerra: los atenienses no confían tanto en los preparativos previos ( $\pi \alpha \rho \alpha \sigma \kappa \varepsilon v \alpha i \tilde{\zeta})$ y en las

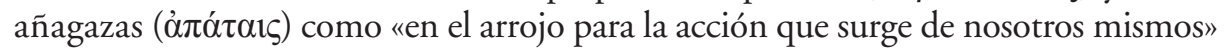

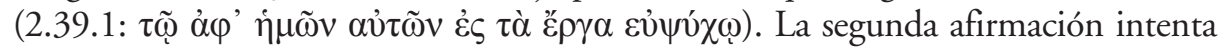
explicar los motivos de este diferente comportamiento ofreciendo una directa

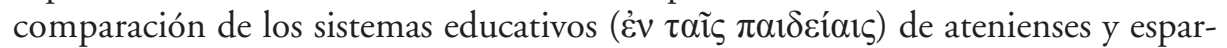
tanos: «mientras unos desde la temprana juventud intentan conseguir el valor con

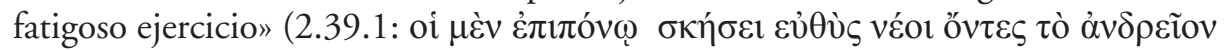

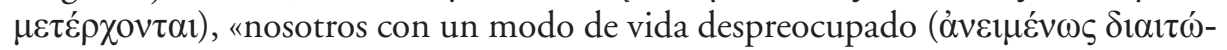
$\mu \varepsilon v o l)$ no somos más remisos en ir a peligros similares».

La segunda idea es que los escoliastas tenían muy claro que la definición de la democracia puesta por Tucídides en boca de Pericles en 2.37 .1 no podía ser vista como un simple elogio de este régimen político en clave de democracia radical. De manera evidente, consideran que en este pasaje no se indica que el poder

Cf. Fischer (1913) y Maehler (2007). La importancia de este papiro es que nos muestra cómo este pasaje era conocido en la época imperial y resuelve definitivamente algunas discusiones de tipo textual que

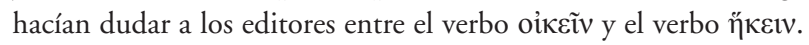

${ }^{43}$ Hude (1927: 130). Sobre el sentido del verbo aiví $\tau \varepsilon \tau \alpha$ เ como 'to allude to', 'adumbrate' en el ámbito de los escolios, cf. Nünlist (2009: 225-231 y 368). 
político esté en manos del pueblo, sino que Pericles hace referencia a un régimen político en el que una élite administraba en favor del pueblo y que, en la práctica, era de tipo aristocrático por su insistencia en el papel de la areté. De hecho, en primer lugar,

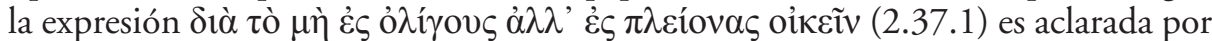

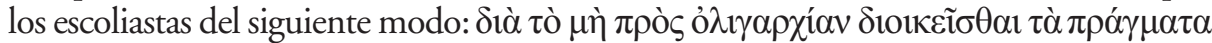

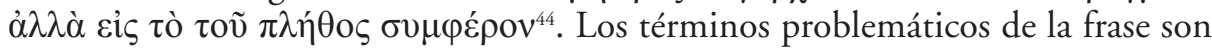

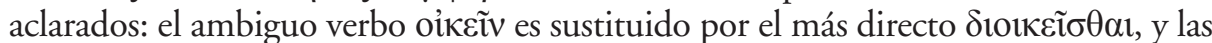

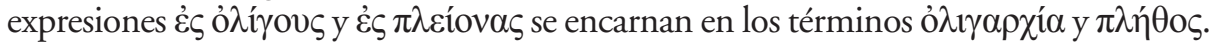
La explicación aportada incide con toda claridad en que el régimen político se deno-

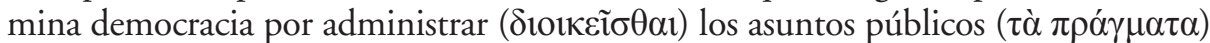

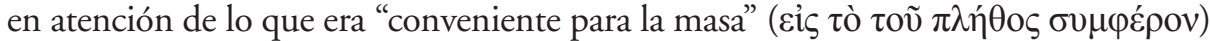

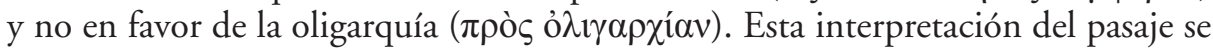
complementa, en segundo lugar, por la importante afirmación de que "la demo-

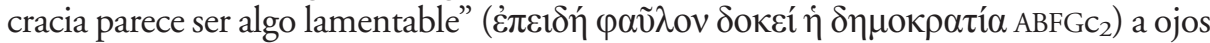
de Tucídides ${ }^{45}$. El escoliasta claramente atribuye al historiador esta idea sobre la democracia radical, al establecer una directa conexión con otro pasaje importante de la obra del historiador, donde, al hacer el elogio póstumo de Pericles, tras la muerte del político ateniense a consecuencia de la peste del 429 , nos informa de que Tucídides pensaba que, bajo Pericles, el admirado régimen político de Atenas "de nombre era una democracia, pero de hecho era el gobierno del primer ciudadano" (Thuc. 2.65.9:

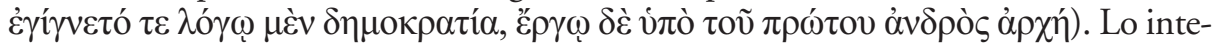
resante es que, con la vista puesta en este pasaje tucidideo, el escoliasta ha empleado

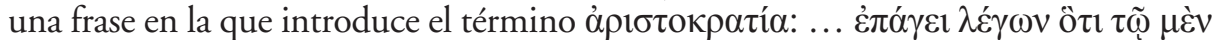

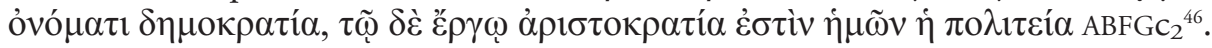
Según el escoliasta, Tucídides pensaba que la politeía ateniense en tiempos de Pericles

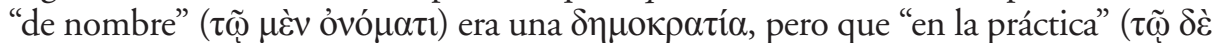

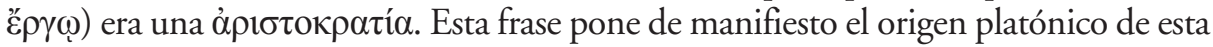
idea expresada en los escolios, ya que este texto ha de entenderse como una alusión a un famoso pasaje del Menéxeno 238c-d, donde se señala lo siguiente sobre la politeía como "alimento de los hombres":

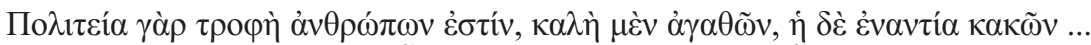

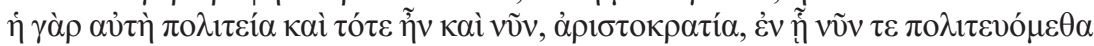

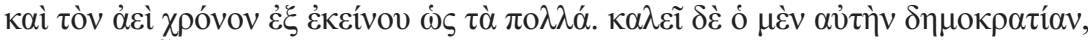

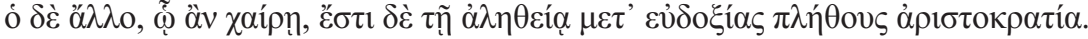
Porque un régimen político es alimento de los hombres: de los hombres buenos, si es bueno, y de los malos, si es lo contrario ... Pues estaba vigente entonces, como ahora, el mismo sistema político, un gobierno de los mejores ( $\alpha \rho \imath \sigma \tau о \kappa \rho \alpha \tau i ́ \alpha)$, que

\footnotetext{
${ }^{44}$ Cf. Hude (1927: 131).

${ }^{45}$ Cf. Hude (1927: 131).

${ }^{46}$ Cf. Hude (1927: 131).
} 
actualmente nos rige y que desde aquella epoca se ha mantenido la mayor parte del tiempo. Unos lo llaman democracia, otros le dan otro nombre, según les place, pero es, en realidad, una aristocracia con la aprobación de la masa.

Una afirmación platónica que ha sido interpretada como una referencia directa tanto a las palabras pronunciadas por Pericles en 2.37.1 (ővo $\mu \alpha \ldots \delta \eta \mu о \kappa \rho \alpha \tau i ́ \alpha$

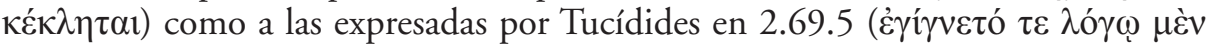
$\delta \eta \mu о к \rho \alpha \tau i ́ \alpha . ..)^{47}$. Un pasaje en el que el filósofo dejaba perfectamente claro que

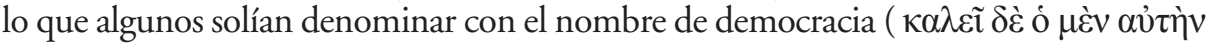

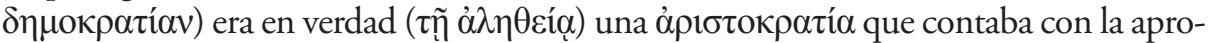

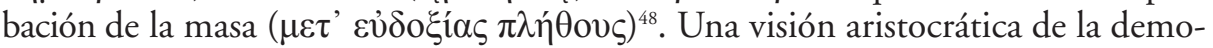
cracia ateniense que, además, sería coherente con la insistencia por parte de Pericles de la importancia de la areté frente a la pertenencia a un grupo social o político para

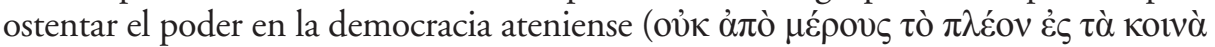

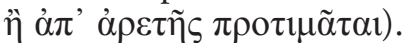

Así, en tercer lugar, de manera coherente con esta idea, la expresión ov̉к ảjò

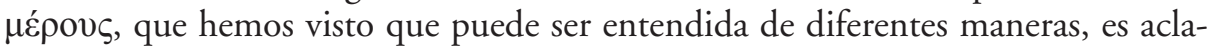
rada por los escoliastas haciendo referencia concreta al reparto del territorio dorio que llevaron a cabo los reyes Heraclidas de los laconios, donde primó la existencia

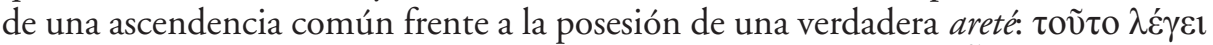

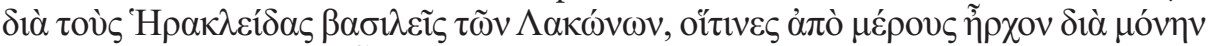

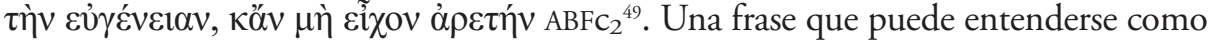
una adaptación del texto tucidideo, al resaltarse que esos reyes se distribuían el poder

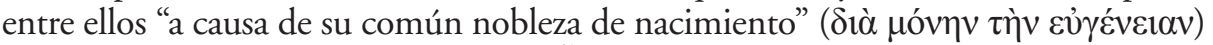

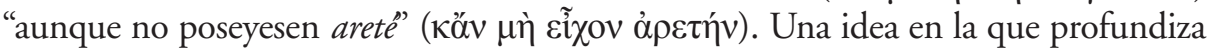

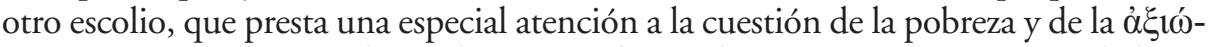

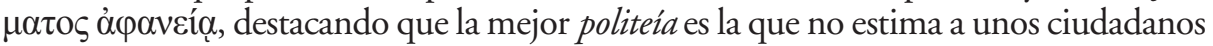

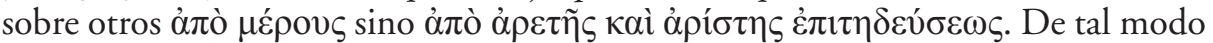
que el que sea de este modo, aunque pertenezca a los pobres y a los que no poseen

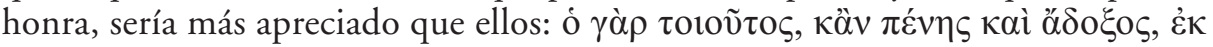

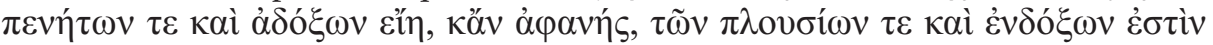

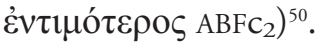

2.2. Desde nuestro punto de vista, la interpretación de 2.37.1 que defienden estos escolios es claramente deudora de la tradición negativa del personaje de Pericles

${ }^{47}$ Sobre los paralelismos entre Tucídides y Platón en este pasaje, cf. Labriola (1980).

${ }^{48}$ Cf. Monoson (1998: 492-493): "when Socrates moves to describe the constitution that nourished the men of Athens, he uses language that echoes Thucydides' contention that Pericles ruled at Athens as 'first man'".

${ }^{49}$ Cf. Hude (1927: 131).

${ }^{50}$ Cf. Hude (1927: 132). 
a lo largo de la Antigüedad ${ }^{51}$. De hecho, desde los testimonios que nos han dejado otros autores de finales del siglo $\mathrm{V}$ a.C. y principios del siglo IV a.C., como los poetas cómicos (muy críticos con los rasgos autoritarios de la figura de Pericles) ${ }^{52}$ o Platón, hasta su principal biógrafo, Plutarco, todos ponen de manifiesto que los antiguos no veían del mismo modo que hoy en día ni a Pericles ni a la definición de democracia que se ofrece en 2.37.1. Un aspecto que ha de tenerse en cuenta por parte de quienes consideran que el discurso de Pericles se ajusta a lo realmente pronunciado al tener presente Tucídides a un público que pudo haber conocido de primera mano el epitafio. Y es que su emisor, Pericles, no fue considerado por todos sus contemporáneos como un auténtico adalid de la democracia sino que muchos lo vieron como uno de los principales causantes de la derrota de Atenas en la Guerra del Peloponeso y de la degeneración de su régimen político ${ }^{53}$. Una tradición que, de manera un tanto contradictoria, presenta a Pericles en unos casos introduciendo costumbres demagógicas como la misthophoría y, en otros, como un político que condujo férreamente a las masas. Datos que ayudan a comprender que para los críticos antiguos estas palabras de Pericles sobre la politeía ateniense tenían que verse con cierta prevención. En unos casos por los efectos negativos de una medida tan demagógica como la misthophoría. En otros casos, por el modo en que Pericles condujo a Atenas. De hecho, Canfora adelantó la discutida hipótesis de que esta era la primera vez que fue acuñado con un sentido político el término princeps $^{54}$. Una afirmación que se conecta directamente con lo que el propio Tucídides relata que pasó después de la muerte de Pericles (2.69.10), cuando políticos mediocres no consiguieron liderar firmemente a las masas y, ante la ausencia de un auténtico estadista, cedieron de verdad el poder al pueblo (algo que es visto de manera poco favorable por el historiador) y generaron por ello una auténtica catástrofe para la pólis ${ }^{55}$ :

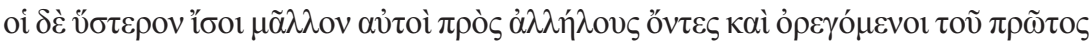

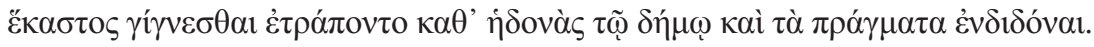
En cambio, los políticos posteriores, por estar más igualados entre sí y sin embargo aspirar cada uno a ser el primero, llegaban incluso a entregar al pueblo la dirección de los asuntos públicos para congraciarse con él.

${ }^{51}$ Cf. Banfi (2003), Azoulay (2010: 158-163).

${ }^{52}$ Sobre la opinión poco favorables de la comedia, cf. Vickers (2011).

${ }^{53}$ Cf. el cuadro expuesto por Mossé (2007: 197-198) y por Pébarthe (2010: 463-464).

${ }^{54}$ Cf. Canfora (2004: 9). Al respecto, cf. la definición del régimen democrático como una aristocracia con la aprobación del pueblo en Plat. Menex. 238d. Frente a esta interpretación, cf. Musti (1995).

${ }^{55}$ Cf. Cartledge (2016: 115-116): "To the conservative, non-democratic Thucydides, who liked to imagine Pericles as a sort of uncrowned King raised above the hurly-burly of mundane politicking ... he made the triumph of demagoguery into a key part of his explanation for Athens' defeat in the Peloponnesian War”. 
2.3. Una impresión que es corroborada por su principal biógrafo antiguo, Plutarco, quien, en la Vida dedicada al político ateniense, destaca de manera especial el inmenso poder que alcanzó Pericles en el seno de la ciudad ${ }^{56}$. Este férreo dominio tuvo el efecto positivo de que las tradicionales divisiones políticas cesasen y que la ciudad viviese una armonía digna de admiración. Uno de los factores con los que Plutarco intenta contrarrestar la enorme influencia de esa tradición negativa para construir un cuadro más positivo del personaje ${ }^{57}$. Pero, como contrapartida, Plutarco también destaca que esto solo pudo conseguirse gracias al control total de Atenas y de todo lo que dependía de los atenienses (15.1). En la práctica, tal y como pone de manifiesto el filósofo de Queronea, Pericles terminó por ejercer un poder muy superior al de muchos reyes y tiranos que se plasmó en una politeía que es calificada como "aristocrática y regia" (15.2: ஷ̉ Algo que, según Plutarco, fue corroborado por los poetas cómicos contemporáneos, quienes "consideran a sus compañeros de filas como nuevos pisistrátidas y le incitan a jurar que él no será un tirano, sugiriendo de este modo que su superioridad era dema-

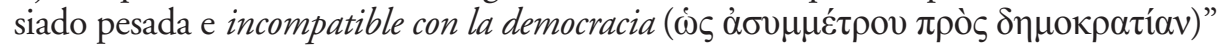
(16.1). Plutarco, heredero de esa tradición negativa sobre Pericles que se remonta a Platón y a los cómicos, nos informa de manera claramente concordante con lo que señalan los escolios que ya en época imperial romana se tenía claro que la figura y la política de Pericles eran incompatibles con la democracia radical que parece alabar en su discurso ${ }^{58}$. Una visión que, sin duda, tendría que determinar el modo en que sus contemporáneos entendían la definición de democracia expuesta en 2.37.1.

2.4. Esa visión negativa de Pericles, visible en los escolios, también está detrás de uno de los juicios antiguos más negativos que se conservan con respecto al epitafio. De hecho, un crítico de época imperial como Dionisio de Halicarnaso consideró que este epitafio no era apropiado y que el historiador Tucídides se equivocó al insertarlo en esta parte de su obra. En su opinión, la ocasión no lo merecía $a^{59}$. Afirma que "en cualquier libro convenía más que en ése pronunciar dicho discurso fúne-

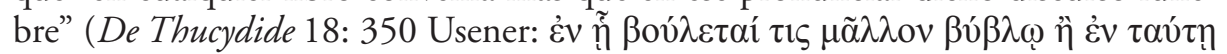

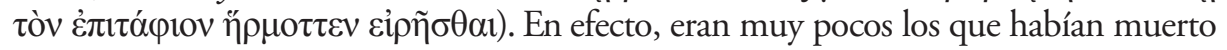
en el primer enfrentamiento de la guerra, no habían hecho nada brillante y, además, hubiera sido más adecuado insertar un epitafio más adelante. Por ejemplo, tras la terrible derrota en Sicilia que costó la muerte a la mayor parte de los atenienses que conformaban la expedición. Pero lo más interesante son las opiniones personales que Dionisio vierte sobre el orador y sobre el discurso. La primera refleja una clara ironía,

\footnotetext{
${ }^{56}$ Sobre la imagen de Pericles en Plutarco, cf. Powell (2010).

${ }^{57}$ Cf. la lectura detallada de Banfi (2003: 215-246) sobre "la construzione di un modelo ideale".

${ }^{58}$ Cf. Stadter (1987) y Stadter (1989) para un análisis de estos pasajes en profundidad.

${ }^{59}$ Cf. Kendrick Pritchett (1975) ad loc.
} 
al señalar que el historiador "introduce a Pericles, el más ilustre de los demagogos, para pronunciar aquella oración tan elevada, digna de una tragedia" (351 Usener:

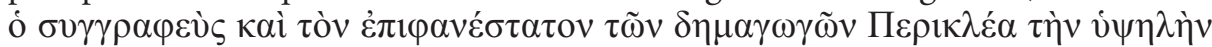

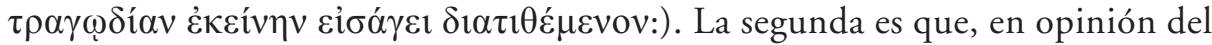
crítico, la causa era que Tucídides deseaba "utilizar la persona de Pericles y componer un discurso fúnebre como si lo hubiera pronunciado aquel" (352 Usener: $\tau \tilde{\omega}$

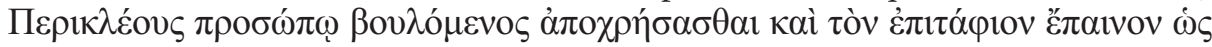
vं $\pi^{\prime} \dot{\varepsilon} \kappa \varepsilon i ́ v o v$ $\left.\eta \theta \dot{\varepsilon} v \tau \alpha \sigma v v \theta \varepsilon \tilde{i} v \alpha \mathrm{l}\right)$. Una afirmación que cuadraría perfectamente a quienes consideran que Tucídides ha buscado caracterizar a Pericles. La tercera es que critica que Tucídides "reservara para un hecho insignificante y sin importancia un elogio que estaba por encima del mérito de aquella acción" (De Thucydide 18:

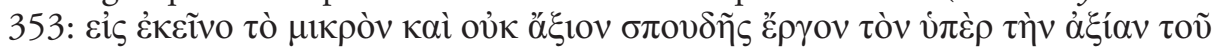

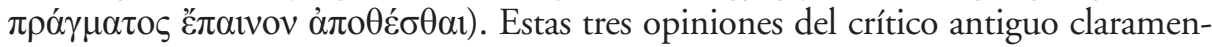
te ponen en cuarentena al conjunto de este discurso fúnebre y, de manera especial, los pasajes en los que Pericles ofrecía su visión sobre la democracia. Para Dionisio todo el contenido de este discurso "elevado" e "inapropiado" ha de ser entendido como una creación del historiador puesta en boca del político. Una crítica que respondía a motivos retóricos y formales (el poco ajuste, "conveniencia", de la ocasión) pero que también se debía a las evidentes prevenciones con respecto al personaje que lo pronunció (definido significativamente como "el más ilustre de los demagogos") y a su contenido (discurso elevado digno de una tragedia). Es evidente que, a la vista de estos juicios sobre orador y sobre el discurso en su conjunto, no era posible para autores como Dionisio de Halicarnaso un enjuiciamiento positivo de 2.37.1 como un simple elogio de la democracia sino como un texto que había sido puesto conscientemente en boca de Pericles con todas las implicaciones que pueden deducirse de ello.

2.5. Finalmente, algunos pasajes de la retórica tardía nos permiten comprobar hasta qué punto se asentó la interpretación de 2.37.1 defendida por los escolios y hasta qué punto habría influido en ámbitos tan formalizados como el de la escuela. Quizás el ejemplo más llamativo de la influencia del epitafio de Pericles lo aporta un autor de la Antigüedad tardía como Libanio en sus progymnásmata ${ }^{60}$. En el apartado dedicado a los tópicos comunes, hay una parte de la declamación Contra el tirano

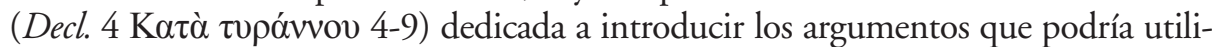
zar alguien que defienda la democracia. Libanio al describir la politeía que el tirano

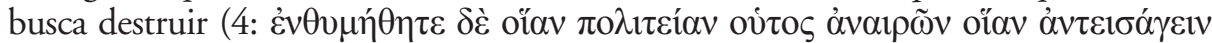
$\dot{\varepsilon} \pi \varepsilon \chi \varepsilon i ́ p \eta \sigma \varepsilon v)$ pasa revista a una visión idílica de la democracia en la que hay una boulé que decide con antelación, un pueblo que participa en la ekklesía y unos tribunales que defienden a los que sufren injusticia y castigan a los que la cometen $(D e c l$. 4:

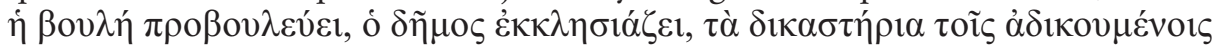

${ }^{60}$ Cf. Gibson (2004). 
àuv́vel ...). La tribuna está abierta a cualquiera que quiera hablar, pero se castiga a quien persuade de lo que no es conveniente y se estima a quien dice lo que es preciso

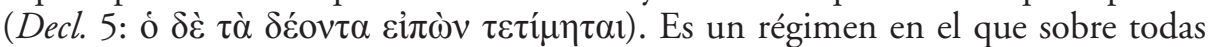

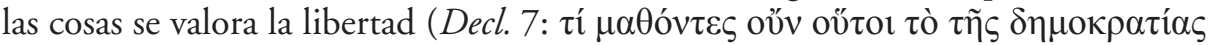

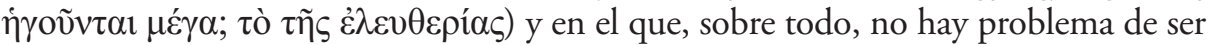

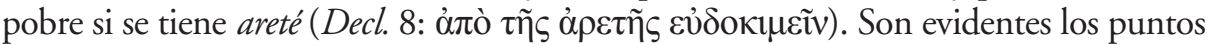
de contacto con el texto tucidideo. No obstante, el punto culminante es el pasaje en el que Libanio señala en qué consiste la democracia:

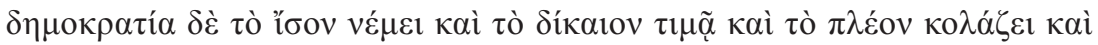

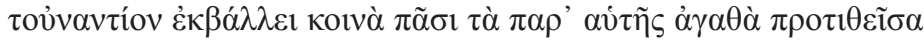

La democracia administra la igualdad, honra la justicia, castiga el exceso y aleja lo contrario, estableciendo que los bienes comunes que se derivan de ella sean compartidos por todos.

Desde nuestro punto de vista, Libanio claramente está haciendo alusión a 2.37.1 en este texto laudatorio, interpretando que la democracia es un régimen

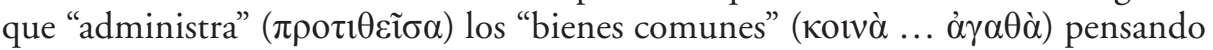
en "todos" $(\pi \tilde{\alpha} \sigma \imath)^{61}$. Aunque el pueblo participa en la asamblea (cf. ó $\delta \tilde{\eta} \mu \circ \varsigma \dot{\varepsilon} \kappa \kappa \lambda \eta-$ $\sigma t a ́ \zeta \varepsilon 1)$, Libanio no incide en su papel activo sino que es visto claramente como sujeto pasivo. En cierto modo, es como si esta definición netamente escolar personificase a la democracia como un ente que se ocupa de estas tareas. En definitiva, un exponente del grado en que la interpretación defendida por los escoliastas del texto había calado en la cultura escolar del mundo antiguo.

\section{CONCLUSIONES}

Las interpretaciones antiguas de este pasaje ambiguo de Tucídides (2.37.1) ponen de manifiesto la influencia decisiva que ejercieron motivos de tipo ideológico. Nuestro trabajo ha puesto de manifiesto el modo en el que el peso de la tradición crítica sobre la figura de Pericles y sobre los defectos del régimen democrático en Atenas ha estado detrás de la interpretación de este pasaje clave del epitafio más extendida a lo largo de toda la Antigüedad. Esa extensa tradición negativa sobre Pericles y la democracia basada en los excesos del régimen democrático que condujeron a Atenas a la decadencia ejerció una influencia clave. Ese enfoque influyó decisivamente sobre la interpretación defendida por los escoliastas de Thuc. 2.37.1, que no podían dejar de lado la autoridad de autores como Platón y Plutarco al enjuiciar tanto al personaje

${ }^{61}$ Cf., no obstante, la interpretación de Gibson (2008: 181, n. 19): “This brief ode to democracy seems to have been inspired by Pericles' funeral oration (especially Thucydides 2.37.1)”. 
de Pericles como al momento histórico que le tocó vivir. Y esta visión es la que acabó determinando la versión defendida por numerosos autores posteriores hasta la Antigüedad tardía, con evidentes influjos sobre la cultura escolar. Es ahí donde radica la interpretación acogida por una parte de la crítica moderna, para la cual estas palabras de Tucídides reflejarían la verdadera ideología del líder ateniense, dejando entrever, gracias al empleo de conceptos propios de un lenguaje de tipo oligárquico, una visión "aristocrática" de la democracia.

Otra cuestión diferente es cómo continuó y se matizó esta interpretación del texto tucidideo en épocas posteriores, como el Renacimiento y la Edad Moderna, en las que surgieron nuevas interpretaciones del concepto de democracia que, viendo la Atenas de Pericles como el más ilustre antecedente de nuevos experimentos políticos, acabaron llevando a los sucesivos traductores a adoptar otros enfoques que han sido decisivos para la interpretación moderna de este texto. Una tarea que acometeremos en un próximo trabajo.

\section{BIBLIOGRAFÍA}

Andrewes, J. A. (2004): «Pericles on the Athenian Constitution (Thuc. 2.37)», AJPh 125: 539-561.

Azoulay, V. (2010): Périclès: La démocratie athénienne à l'épreuve du grand homme, Armand Colin, París.

BAnfi, A. (2003): Il governo della città: Pericle nel pensiero antico, Il Mulino, Bolonia.

Bosworth, A. B. (2000): «The historical context of Thucydides' Funeral Oration», JHS 120: 1-16.

BRoCK, R. (1991): «The Emergence of Democratic Ideology», Historia 40: 160-9.

Caballero López, J. A. (1982): «Aportaciones al estudio lingüístico de la República de los Atenienses», Cuadernos de investigación filológica 8: 61-102.

CAnfora, L. (1986): Tucidide, La guerra del Peloponneso, Laterza, Roma-Bari.

Canfora, L. (2004): Democracia. Historia de una ideología, Crítica, Barcelona.

Cartledge, P. (2016): Democracy. A Life, University Press, Oxford.

Christodoulou, P. (2013): «Thucydides' Pericles. Between Historical Reality and Literary Representation", en A. TSAKMAKIS - M. TAMIOLAKI (eds.), Thucydides Between History and Literature, De Gruyter, Berlín - Boston, pp. 225-257.

Classen, J. - Steup, J. (1914): Thukydides, vol. II, Berlín.

Connor, W. R. (2018): «Pericles on Democracy: Thucydides 2.37.1», CW 111: 165-175.

Dabdab Trabulsi, J. A. (2011): Le Présent dans le Passé. Autour de quelques Périclès du XX siècle et de la possibilité d'une verité en Histoire, Presse Universitaires de Franche-Conté, Beçanson.

DoninI, G. (1969): La posizione di Tucidide verso in governo dei cinquemilla, Paravia, Turín.

EDMunds, L. (1975): Chance and Intelligence in Thucydides, University Press, Harvard.

FanTaSIA, U. (2003): La Guerra del Peloponneso. Libro II Tucidide, Pisa: ETS.

Finley, M. I. (1960): «Athenian Demagogues», Past and Present 21: 3-24.

FINLEY, M. I. (1980): Vieja y nueva democracia y otros ensayos, Ariel, Barcelona.

FisCher, F. (1913): Thucydidis reliquiae in Papyris et Membranis Aegyptiacis servatae, Teubner, Leipzig. 
Flashar, H. (1969): Der Epitaphios des Perikles. Seine Funktion im Geschichtswerk des Thukydides, Heidelberg.

ForsdyKe, S. (2001): «Athenian Democratic Ideology and Herodotus' Histories», AJPh 122: 329-358.

Foster, E. (2010): Thucydides, Pericles, and Periclean Imperialism, University Press, Cambridge.

Fromentin, V. - Gotteland, S. - Payen, P. (eds.) (2010): Ombres de Thucydide. La reception de l'historien depuis l'Antiquité jusqu' au debut du XX' Siècle, Ausonius, Bordeaux.

Gibson, C. A. (2004): «Learning Greek History in the Ancient Classroom: The Evidence of the Treatises on Progymnasmata», CPh. 99: 103-129.

Gibson, C. A. (2008): Libanius's Progymnasmata: Model Exercises in Greek Prose Composition and Rhetoric, Society of Biblical Literature, Atlanta.

Gomme, A. W. (1948): «Thucydides Notes», CQ 42: 10-14.

Gomme, A. W. (1956): A Historical Commentary on Thucydides, Vol. II, Clarendon Press, Oxford.

Grant, J. R. (1971): «Thucydides 2.37.1», Phoenix 25: 104-107.

GreEnwood, E. (2015): «On translating Thucydides», en Ch. LeE - N. Morley (eds.), A Handbook to the Reception of Thucydides, Wiley-Blackwell, Malden, MA - Oxford, pp. 91-121.

Grethlein, J. (2005): «Gefahren des logos: Thukydides' Historien und die Grabrede des Perikles», Klio 87: 41-71.

Grethlein, J. (2010): The Greeks and their Past. Poetry, Oratory and History in the Fifth Century BC, University Press, Cambridge.

Hansen, M. H. (2008): «Thucydides' Description of Democracy (2.37.1) and the EU-Convention of 2003", GRBS 48: 15-26.

Harris, E. M. (1992): «Pericles' Praise of Athenian Democracy. Thucydides 2.37.1», HSCP94: 157-167.

Hornblower, S. (1991): A Commentary on Thucydides (Books I-III), vol. I, Oxford: Clarendon Press.

Hornblower, S. (2000): «The Old Oligarch (Pseudo-Xenophon's Athenaion Politeia) and Thucydides.

A Fourth-Century Date for the Old Oligarch?», en P. Flensted-Jensen - Th. H. Nielsen L. Rubinstein (eds.), Polis \& Politics: Studies in Ancient Greek History, University of Copenhagen - Museum Tusculanum Press, Copenhague, pp. 363-384.

Hude, K. (ed.) (1927): Scholia in Thucydidem ad optimos codices collata, Teubner, Leipzig.

IgLEsias-Zoido, J. C. (2006): «El sistema de engarce narrativo en los discursos de Tucídides», Talia dixit 1: 1-25.

IgLESIAS-Zoido, J. C. (2011): El legado de Tucídides en la cultura occidental. Discursos e historia, Universidade de Coimbra, Coimbra.

Jones, A. H. M. (1957): Athenian Democracy, Blackwell, Oxford.

Kagan, D. (1991): Pericles of Athens and the Birth of Democracy, The Free Press, Nueva York.

KaKRIDIS, J. (1961): Der thukydideische Epitaphios. Ein stilistischer Kommentar. Munchen.

Kendrick PritchetT, W. (1975): Dionysius of Halicarnassus, On Thucydides, University of California Press, Los Ángeles.

KIRKWOOD, G. M. (1972): «Thucydides Judgement of the Constitution of the Five Thousand (VIII 97.2)», AJPh 93: 92-103.

Kleinlogel, A. (1964): «Beobachtungen zu den Thukydidesscholien I», Philologus 108: 233-246.

Kleinlogel, A. (1998): «Beobachtungen zu den Thukydidesscholien II», Philologus 142: 11-40. 
KLeInlogel, A. (2011): «Beobachtungen zu den Thukydidesscholien III», Philologus 155: 257-271.

Kleinlogel, A. - Alpers, K. (2019): Scholia graeca in Thucydidem. Scholia vetustiora et Lexicon Thucydideum Patmense, Walter de Gruyter, Berlín - Nueva York.

Labriola, I. (1980): «Tucidide e Platone sulla democrazia ateniese», QS 6: 207-229.

LAmberT, J. - Robyns, C. (1997): «Translation», en R. Posner - K. Robering - Th. A. SEbeOK (eds.), Semiotics: A Handbook on the Sign - Theoretic Foundations of Nature and Culture, W. de Gruyter, Berlín, pp. 3594-3614.

Landman, G. P. (1974): «Das Lob Athens in der Grabrede des Perikles», MH 31: 65-95.

Lehmann, G. A. (2008): Perikles: Staatsmann und Stratege im klassischen Athen, C. H. Beck, Múnich.

LongO, O. (2000): Epitafio di Pericle per i caduti del primo anno di guerra (II, 34-47), Marsilio, Venecia.

LORAUX, N. (1981): Linvention d'Athènes. Histoire de L'oraison funèbre dans la 'cité classique', París - La Haya - Nueva York [trad. esp. 2012: La invención de Atenas. Historia de la oración fúnebre en la 'ciudad clásica', Katz, Buenos Aires - Madrid].

Luschnat, O. (1954): «Die Thukydidesscholien: Zu ihrer handschriftlichen Grundlage, Herkunft und Geschichte», Philologus 98: 14- 58.

LuZZATTO, M. J. (1993): «Itinerari di codici antichi: un'edizione di Tucidide tra il II ed il X secolo», MD 30: 167-203.

MaeHler, H. (2007): «Das Thukydides-Hypomnema P.Oxy. 853 und die Scholien», en J. FröSÉN T. Purola - E. Salmenkivi (eds.), Proceedings of the $24^{\text {th }}$ International Congress of Papyrology, Helsinki, 1-7 August, 2004, vol. II, Societas Scientarum Fennica, Helsinki, pp. 587-593.

Martin, Th. R. (2016): Pericles, a Biography in Context, University Press, Cambridge.

Momigliano, A. (1960): «Reseña de E. A. Havelock, The Liberal Temper in Greek Politics», Rivista Storica Italiana 72: 534-541.

Monoson, S. S. (1998): «Remembering Pericles: The Political and Theoretical Import of Plato's Menexenus», Political Theory 26: 489-513.

Mossé, C. (2007): Pericles. El inventor de la democracia [trad. esp.], Espasa, Madrid.

Musti, D. (1995): Demokratía. Origini di un' idea, Laterza, Roma - Bari [trad. esp. 2000, Alianza, Madrid].

Nichols, M. P. (2015): Thucydides and the Pursuit of Freedom, Cornell University Press, Ithaca.

NüNLIST, R. (2009): The Ancient Critic at Work. Terms and Concepts of Literary Criticism in Greek Scholia, University Press, Cambridge.

Ober, J. (1989): Mass and Elite in Democratic Athens, Princeton University Press, Princeton.

Ober, J. (2011): Political Dissent in Democratic Athens: Intellectual Critics of Popular Rule, Princeton University Press, Princeton.

Oliver, J. H. (1955): «Praise of Periclean Athens as a Mixed Constitution», RhM 98: 37-40.

Osborne, R. (2004): The Old Oligarch: Pseudo-Xenophon's Constitution of the Athenians [2a ed.], LACTOR (London Association of Classical Teachers - Original Records), Londres.

Ostwald, M. (1987): From Popular Sovereignty to the Sovereignty of Law: Law, Society, and Politics in Fifth-Century Athens, University of California Press, Los Ángeles.

PAVÓn, J. M. (1946): Tucídides. Libro II, CSIC, Madrid [reed. Ediciones Clásicas, Madrid, 1991].

PéBARTHE, Ch. (2007): «La question de la clientèle en Grèce ancienne: Cimon versus Péricles, patronage privé contre patronage communautaire?», en V. LÉCRIVAIN (ed.), Clientèle guerrière, clientèle 
foncière et clientèle électorale. Histoire er anthropologie, Editions Universitaires de Dijon, Dijon, pp. 173-197.

Pébarthe, Ch. (2010): «Périclès, au-delà de Thucydide», en V. Fromentin - S. GotTeland - P. PaYen (eds.), Ombres de Thucydide. La reception de l'historien depuis l'Antiquité jusqu' au debut du $X X^{e}$ Siècle, Ausonius, Bordeaux, pp. 463-490.

PohlenZ, M. (1948): «Zu den attischen Reden auf die Gefallenen», SO 26: 46-74.

Poppo, E. F. (1834): Thucydidis de Bello Peloponnesiaco, vol. III, parte 2, Leipzig.

Powell, A. (2010): «Périclès chez Thucydide et chez Plutarque», en V. Fromentin - S. GotTeland P. PAYEN (eds.), Ombres de Thucydide. La reception de l'historien depuis l'Antiquité jusqu' au debut du XXe Siècle, Ausonius, Bordeaux, pp. 93-104.

RaAflaub, K. A. (1990): "Contemporary Receptions of Democracy in Fifth Century Athens», en W. R. Connor - M. H. Hansen - K. A. RaAflaub - B. S. Strauss (eds.), Aspects of Athenian Democracy, Museum Tusculanum Press, Copenhague, pp. 33-70.

RaAflaub, K. A. (1997): "Power in the Hands of the People: Foundations of Athenian Democracy», en I. Morris - K. RaAflaub (eds.), Democracy 2500? Questions and Challenges, Archaeological Institute of America, Dubuque, pp. 31-66.

Regenbogen, O. (1949): Thukydides. Politische Reden, Leipzig.

Rhodes, P. J. (1988): Thucydides. History II, Aris \& Phillips, Warminster.

Rhodes, P. J. (2003): Ancient Democracy and Modern Ideology, Duckworth, Londres.

Romilly, J. DE (1947): Thucydide et l'impérialisme athénien: la pensée de l'historien et la genèse de l'ouvre, Les Belles Lettres, París.

Romilly, J. DE (1962): Thucydide. La Guerre du Péloponnèse, vol. II, Les Belles Lettres, París.

Romilly, J. DE (1990): La construction de la verité chez Thucydide, Julliard, París.

Rusten, J. S. (1989): Thucydides. The Peloponnesian War. Book II, University Press, Cambridge.

Samons II, L. J. (2016): Pericles and the Conquest of History: A Political Biography, University Press, Cambridge.

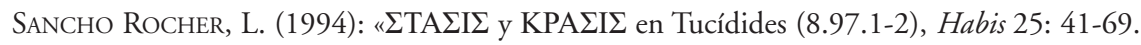

SCHADEWALDT, W. (1929): Das Geschichtschreibung des Thukydides, Berlín.

SCHWARTZ, E. (1919): Das Geschichtswerk des Thukydides, Bonn.

Sheppard, J. G. - Evans, L. (1870): Notes on Thucydides, Longmans, Londres.

SiCKING, M. J. (1995): «The General Purport of Pericles' Funeral Oration and Last Speech», Hermes 123: $404-425$.

Stadter, P. A. (1987): «The Rhetoric of Plutarch's Pericles, Ancient Society 18: 251-259.

STAdTer, P. A. (1989): A Commentary on Plutarch's Pericles, University of North Carolina Press, Chapel Hill - Londres.

Ste. Croix, G. E. M. DE (1956): «The Constitution of the Five Thousand», Historia 5: 1-23.

Strasburger, H. (2009): «Thucydides and the political self-portrait of the Athenians», en J. S. RUSTEN (ed.), Thucydides, University Press, Oxford, pp. 191-219.

TurasieWICZ, R. (1995): «Pericles' Funeral Oration in Thucydides and its Interpretation», Eos 83: 33-41.

Vickers, M. (2011): Pericles on Stage: Political Comedy in Aristophanes' Early Plays, University Press, Texas. 
VIDAL-NAQUET, P. (1990): La démocratie grecque vue d'ailleurs: Essais d' historiographie ancienne et moderne, Flammarion, París.

Vlastos, G. (1964): «Isonomía Politiké», en J. MAU - E. G. SCHMIDT, Isonomia: Studien zur Gleichheitsvorstellung im griechischen Denken, Berlín, pp. 1-35.

VRETSKA, H. (1966): «Perikles und die Herrschaft des Würdigsten, Thuk. II 37.1», RhM 109: 108-120.

Warner, R. (1954): Thucydides. History of the Peloponnesian War, Penguin, Londres.

WiLL, W. (2003): Thukydides und Perikles. Der Historiker und sein Held, Habelt, Bonn.

WILL, W. (2016): «Democracy without an Alternative: Thucydides, Sparta, and Athens», en Ch. R. THAuER

- Ch. Wendt (eds.), Thucydides and Political Order. Lessons of Governance and the History of the Peloponnesian War, Palgrave Macmillan, Nueva York, pp. 55-73.

Winton, R. I. (2004): «Thucydides 2.37.1: Pericles on Athenian Democracy», RhM 147: 26-34.

ZiolKOwSKI, J. (1981): Thucydides and the Tradition of Funeral Speeches at Athens, Arno Press, Nueva York. 
